\title{
Critical success factors in implementing knowledge management in consultant firms for Malay- sian construction industry
}

\author{
Azlan Othman ${ }^{a^{*}}$, Syuhaida Ismail ${ }^{b}$, Khairulzan Yahya ${ }^{a}$, Mohd. Hafis Ahmad
}

${ }^{a}$ Faculty of Civil Engineering, Universiti Teknologi Malaysia, Johor Bharu, Malaysia

${ }^{b}$ UTM Razak School of Engineering and Advanced Technology, Universiti Teknologi Malaysia, Kuala Lumpur, Malaysia

CH R O N I C L E A B S T RACT

Article history:

Received: November 26, 2017

Received in revised format:

March 31, 2018

Accepted: April 4, 2018

Available online:

April 5, 2018

Keywords:

Knowledge management (KM)

Consultant firm

Civil engineering

Malaysian construction industry

Critical success factors (CSFs)

\begin{abstract}
In Malaysia, there has been an argument that the Knowledge Management (KM) practice especially in construction industry has not been commensurable with its status as a developing country. Hence, an initiative that aims to appraise the KM practice amongst consultant firms working in industry of construction in Malaysia becomes the focal point of this study. This aim is achieved by fulfilling its objectives of delving into the understanding of consultant firms on KM practices and exploring the critical success factors (CSFs) of KM implementation in Malaysia. In this paper, the data is studied on a number of statistical analysis tools, namely descriptive analysis, reliability analysis and relative important index (RII). The results obtained from the questionnaire survey clearly showed that most respondents made a claim that KM enhances the decision making in the organization and KM spurs innovations. Few respondents disagreed with the components of KM practices, indicating that these respondents may not be well aware of the importance of KM. About the top ranking of CSFs for KM practices implementation, it is found that "continuous organization support", "leadership demonstration by senior staff/management", "knowledge and sharing culture", "execution of plan", and "continuous learning" make the top five factors very vital to the effective execution of KM by the consultant firms in the construction industry.
\end{abstract}

\section{Introduction}

The industry of construction is acknowledged as one of the major benefactors to the economic growth in Malaysia. A construction can only be successful if the civil engineering design and consultations are good and proper, which require decent engineering knowledge and experience. However, there is a gap in managing the civil engineering knowledge and expertise amongst the consultant firms in the construction industry. According to Cavaleri (2004), KM is described as a procedure which stresses on activities associated with knowledge that open doors for building, adoption, change and usage of knowledge. The goal is to realise the definitive objective of stressing the intellectual capital of organizations that can achieve the final organisational aims. With that, Shankar et al. (2003) stated that to boost the efficiency and the effectiveness while achieving organisational goals, the classification and 
study of KM activities following how knowledge is handled and managed in the organisational executions (Chawla et al., 2018; Sadeghi \& Rad, 2018).

$\mathrm{KM}$ is one of the most current and significant issues prevalent in the business of construction. This business is a knowledge-based industry that has a strong dependency on significant knowledge contribution of a number of experts in a particular project team. Today, the construction industry has become very much competitive. In this daunting environment, the industry is very much leaning on knowledge as its main resource. Unlike before, the conventional factors of production do not serve as the priority means of reference any longer. Chen et al. (2006) asserted that employees must be equipped with knowledge. Hence, to retain and enhance their skills and creativity further, Zanjani et al. (2008) stated that the construction industry needs to nurture their conviction of KM and endorse it as the key business tools as opposed to the traditional resource-intensive initiative. This is because KM has become the upto-date method in consolidating organisational competency (DeTienne \& Jackson, 2001). This is further agreed by Kleindl (2000), who stated that 94 percent of companies saw KM as being strategically pivotal for businesses.

The concept of KM highlights various perspectives and interpretations. Some might see it as the future information and communication (ICT) development. Hansen (1999) named this as the systematisation approach. However, the actual concept of KM goes further than this understanding. KM is a social process which deliberates on the social and human factors (Mason \& Pauleen, 2003). According to Hansen (1999), KM involves people management which necessitates a deep thoughtful perceptive of the social processes and communication forms that promote effective knowledge creation and sharing. This is where the accomplishment of personalisation approaches depends very strongly on cultivating an appropriate organisational environment and culture.

To investigate whether or not consultant firms are ready to implement KM, first of all, it is important to know more and better about the basics of KM implementation. This study may help those associated with the KM implementation in consultant firms by incorporating the results to their organisation. All the factors that give impetus to KM growth in the Malaysian construction industry will have a consequence on future planning, for example, the Construction Industry Master Plan (CIMP). The crucial contribution of this study is for the Malaysian government, which through this KM model, could help the consultant firms supply the most economic and optimum design not only for private sector but also for government sector in this industry.

\section{Literature Review}

The issue of defining knowledge has become the bone of contention between researchers for a long time, leading to multiple philosophies and methodologies. It is not the primary goal of this research to participate in the similar discussion to uncover and discover the "universal truth" of the term knowledge. This is clarified by the truth that the understanding of knowledge will never be the manipulating factor in building the knowledge based theory or engaging key players and researchers' interest in going further into the aspect of managing knowledge. However, Alavi and Leidner (2001) stressed out that it is probably a wise idea to take into account of the diverse perspectives of knowledge as being talked about in the organisational theory literature, strategic management, and information technology, where it will allow us to debunk a few presumptions about knowledge underlying organisational KM processes. We will now start by considering knowledge definitions.

Burton-Jones (1999) highlighted knowledge as a starting point of leading measures in recent business atmosphere that is dynamic, lively and rapidly changing. To administer changes, the importance of individual and organisational knowledge in all the business entities is accentuated (Ikujirō \& Takeuchi, 1995). Knowledge creation, transfer, identification, sharing, acquisition and manipulations are very much important to enhance projects work efficiency and increase organisational competitiveness. 
It has been pointed out by Storey and Quintas (2001) that there has been a fundamental movement from the traditional form of economy to the new trendy knowledge based economy, where pre-eminent strategy for success is largely reliant on the power of knowledge, rapid learning and competency. Hence, the knowledge settling in employees and in organisational routines is fast becoming significant to organisations and additionally, such knowledge is regarded as a very important resource for competitive benefit which is able to be maintained (Anumba Chimay et al., 2005; Davenport \& Prusak, 1998; Wright et al., 2005).

Prior to the birth of the term "knowledge management" as further claimed, the practice of KM had been around for a long time. A number of researches related to KM has been carried out in a number of sectors and industries; namely manufacturing, pharmaceuticals, chemical, financial and the information technology sectors. Nonetheless, limited studies with regards to the construction industry have been carried out. According to Kazi (2005), the construction industry has normally been unenthusiastic to adopt new management models, where they are more comfortable with the conventional ways of working. That said, after showing KM in a more understandable form to the industry, it has been attentiongrabbing, in the sense that the industry players are now more interested and eager to try to see the effect on their organisation. Grant (1996) added that expertise and knowledge built and assembled by a certain construction organisation reflects its strategic assets which play a role as an added value to their competitiveness.

Kamara et al. (2002) stated next that KM could be advantageous for the construction industry by increasing product innovations, shortening the project duration, maintaining high quality outputs and improving customer satisfaction. The growth of organisations in substantial assets will bring some added values and new knowledge to the industry and the organisation itself, through the KM process. According to Snowden (1999), KM will improve project manager's communication within project teams and immediately, this will also improve the process of knowledge sharing between project managers and team members. Understanding KM in construction organisation would make sure that there is an effective sharing of project documents, best practice knowledge, system engineering techniques and project management, lessons learned and appraise and archive the reasoning for tactical and sound decision-making. The understanding of KM will eventually be sufficient to persuade the construction firms to accept KM principles.

\subsection{Previous Study on the Understanding of Knowledge Management}

KM's concept can be debated in various aspects, although it appears to be a simple subject, it can be complicated too. People have their respective individual innate ability in terms of personal knowledge and the manner of using it. Nevertheless, in terms of running an organisational matter, such as development, flow and application of knowledge it sets for a whole new level. Basically, the level of 'bandwidth' of the knowledge course will be depending on trust between the organisation and the specific individuals involved in the project. Organisations have to create an atmosphere of belief cultivated practice and rewards knowledge-sharing in all contexts with regard to mentoring, learning, teamwork, sharing stories and ideas. The authority of an organisation that can rapidly direct its communal mentalaptitude towards prime issues arising without an administration approval needs to be envisioned.

Traditionally, it was believed that people have conveyed knowledge through a progression to the next generation, and as Wiig (1997) stated, knowledge is not a contemporary concept. Few forms were used in ancient cultures to give lessons to the new generation skills and survival techniques. Human resources are substantial to all industries, and they include the construction industry. Davenport and Völpel (2001) mentioned that knowledge management is also about handling people and vice versa. Thus, Roy (2001) stated that the capacity and ability of the workers to use, distribute and generate existent knowledge to make novel ideas is the reflection of their own value towards their organization. Therefore, retaining knowledgeable workers are essential for organisations that function in this 
knowledge era. Some companies had to develop a system that will be able to boost successful creation and consumption of knowledge. This can also help grasp the mechanism techniques and concepts involved in retaining knowledge workers. Various fields within higher learning institutions such as information sciences, cognitive psychology, psychology and educational have endeavoured to penetrate more into the concepts of knowledge building, depository and recovery, distribution and utilization. If knowledge is created solely without being shared among people or units in an organization, the knowledge value is limited. However, Schulz (2001) mentioned that if the knowledge built is unworthy to be shared, then the value of knowledge sharing is meaningless. Davenport and Prusak (1998) added that the knowledge value rises when its frequency of sharing and admittance within the organisation increase. Likewise, focusing on the content of previous studies of organisational learning, knowledge building and knowledge distribution are the two primary parts of the process of learning (Huber, 1991; Schulz, 2001). Fiol and Lyles (1985) described organisational learning as the process of utilizing rich knowledge to develop actions. Hult et al. (2000) added that organisational learning is very much dependent on two interrelated concepts namely the learning process and the learning organisation structure. To meet the aim of this study, the Cooperative learning theory (Johnson \& Johnson, 1989; Johnson et al., 1988; Johnson et al., 1989) was opted. This was seen as a form of organisational learning that emphasises on the knowledge building, the sharing such as knowledge dispersal, and finally the execution of knowledge to acknowledge predominant work results.

The function of coding, storing and transferring knowledge in organizations has been served by organizational routines, reports, procedures, manuals and policies for a long time, administration and organizational practices has recently transforming into a rather knowledge-based (Alavi \& Leidner, 1999). For instance, employee development, best practice transfer, knowledge audits, and benchmarking have indicated that there is already some awareness of the significance of organisational knowledge and impalpable resources as a whole (Grant, 1996). Given the importance of organisational knowledge, this paper also fine-tunes our understanding of KM implementation in organisations.

Other than producing learning and facilitating knowledge sharing environment, a complete understanding of KM will also provide vision and effective leadership in dealing with learning barriers. Actually, $\mathrm{KM}$ will help to transform the direction of an organisation in becoming learning organisation where it is open to the idea of learning new techniques and continuously changes itself based on newly learned knowledge. These changes will help organisations recollect and allocate knowledge internally and making KM a successful implementation. Burton-Jones (1999) added that prior understanding of existing knowledge has the tendency to influence its organisations comprehend new knowledge. It helps organisations to acknowledge the usefulness of contemporary information, bring it together and utilize it for business purpose (Cohen \& Levinthal, 1990). Organisations may learn from past experiences efficiently and exploit them in a much better way. Indeed, Hislop (2003) recommends that there is a call for exploring and developing the current understanding of what tends to influence employees to share their knowledge. Davenport and Prusak (1998) made another point that limited information is known with regard to the favourable environments that encourage people in organisations to indulge in knowledgesharing. To further understand the failing factors that accompany knowledge sharing efforts, a detailed cost benefit analysis need to be done and seen from the perspective of an employee.

\subsection{Previous Study on Critical Success Factor for KM Implementation}

We also need to discuss KM success factors other than the understanding about the implementation of KM. Many researchers (Bassi, 1999; Choi, 2000; Davenport \& Prusak, 1998; Finnerean, 1999; Liebowitz, 1999; Manasco, 1999; Morey, 1998; Skyme, 2000; Trussler, 1998) defined critical success factors (CSFs) as the keys in which acceptable outcomes would result in accomplished competitive performance. Organisations also ought to be conscious and alert of the aspects that will affect the triumph of a knowledge sharing activities. CSFs presented in 1979 by John F. Rockart and the Massachusetts Institute of Technology (MIT), is a method to aid the managements rule out the information 
needs to manage the organisations(Rockart, 1979). Many firms have exerted the best effort to execute $\mathrm{KM}$, but do not rely a great deal on selecting the best approach for doing that. Being able to understand CSFs for KM implementation can help an organisation meet their goals (Valmohammadi, 2010). KM implementations can be caused by various factors and reasons. Leadership, resources, information technology (IT) and culture had been named by previous researchers as the vital precursor to the successful accomplishment of KM. With the realisation of vital role played by KM, organisations are now looking at it as a CSF in borderless high pace society that we are living in today. To build and sustain organisation competencies, knowledge should be provided to the ideal individuals at the ideal timing. Business entities are emerging into entities that are hungry for knowledge where they start to hire more "minds" instead of "hands". Additionally, the need to boost the usefulness of knowledge is also growing. Therefore, knowledge has been dealt exhaustively as well as other physical business assets. Lots of organisations tend to study the area of KM to expand and endure their competency. The necessity to adopt a more organized learning on the CSFs to execute knowledge sharing is in demand.

Saraph et al. (1989) verified that important sections of administration planning and action must be executed to become effective. As for KM, CSFs can be classified as important processes and activities that can guarantee positive results in the implementation. Leaning on the definition as stated earlier, internal organisational factor is essential in executing KM. Important internal factors can be divided into six different categories namely culture, architecture and operations, human and financial resources, technology and facility, strategy and leadership, and KM processes. There are a number of benefits of CSFs include easy understanding of the concept, the fact that it can help addressing main issues, and simple to monitor as well as can be implemented together with the organisation's strategic planning framework. CSFs have to be utilized collaboratively with a planning procedure as it is vital to determine CSFs since it gains attention from people. Isolating CSFs does not do anything to the critical strategic thinking. Chua (1999) mentioned that the insufficient resources of money, time and man power could be allocated in line with the CSFs identification. Hence, business entities should realise the important things which can possibly affect the achievement of knowledge sharing activities. Lacking the awareness and overseeing the mandatory vital factors may possibly impede an organisation determination to apprehend its maximum capacity.

The CSFs in KM, by contrast, can be observed as the practices and activities that must be confronted to make sure that the implementation can be successful. The enhancement of these practices is needed if they are in the system or are created and constructed. To date, an aggregate set of CSFs to practise $\mathrm{KM}$ in the industry is close to nonexistence. Thus, an appropriate set of CSFs that will aid organisations realise the important issues that they have to deal with is very much required when designing and implementing KM initiatives. Depending on the issues discussed, this paper presented CSFs as the controllable internal factors concerning certain organisations. Other external influences such as the environmental and bureaucracy issues are not taken into this study since there is little to be done by the organisation in dealing with these external factors. Guided by the literature, Skyrme and Amidon (1997) claimed that there are several key success factors that may influence KM implementation: knowledge leadership, a knowledge building and sharing culture, a well-rounded technology facility, a closed bonding to a business imperative, a convincing architecture and vision, organized organisational knowledge processes and constant learning. These factors will depend on lessons learned from previous study of practices and experiences of leading organisation which carry out KM.

\section{Methodology/Materials}

This paper is materialised by carrying out a pilot study on 20 respondents constituting 10 percent from actual sample, aiming to examine the feasibility of the actual questionnaire prior to the distribution to the intended sample. The primary data collection for this study is through the questionnaire survey. This is consistent with the claim made by Andi and Minato (2003) and McQueen and Knussen (2002) mentioning that to achieve good result from many respondents, the use of questionnaire survey is not 
only the most practical but also the most economical way. To help the participants to comprehend the questions better, a definition of KM is given in the questionnaire as recommended by Dillman et al. (1999). As Cronbach's alpha of an acceptable range is obtained through the analysis of this pilot survey, shedding light on the content reliability of the questionnaire. The actual questionnaire survey of about 200 respondents from the consultant firms in the northern region of Malaysia, including Perlis, Kedah, Pulau Pinang and Perak, is done. These respondents are chosen from the probability simple random sampling. The variables from the questionnaire survey were extracted from the comprehensive literature review carried out by researchers. Data is analysed by utilizing Statistical Package of Social Sciences (SPSS) version 23.0 on various statistical analysis tools, and they are the descriptive analysis, reliability analysis and relative important index (RII).

\subsection{Statistical Test}

The internal test of consistency items is analysed using the Cronbach's alpha reliability index. Nunnally and Bernstein (1994) suggested that to ascertain the reliability of a study, the value of 0.7 and above can serve as the benchmark. Moreover, Hair et al. (2010) claimed that to indicate if the grouped items are reliable or not, alpha value of above 0.6 may be acceptable. The alpha reliability index is derived from basic descriptive statistics values for example the calculation of the central tendency, the mean, and the dispersion measurement, the standard deviation (Field, 2009; Pallant, 2010). In this study we used 0.7 and above because the reliability level is considered high.

To assess the importance of indicators, Jarkas and Bitar (2012) suggested on the use of Relative Importance Index (RII) analysis, and this same method was adopted in their research. The RII analysis works by calculating weighted score for each indicator through the respondent's data. In addition, (Jarkas \& Bitar, 2012) also stated that the importance of each indicator is described by the RII value. The greater the value of the RII for the indicator, the more significant the indicator is.

The formula serving to calculate the RII, as suggested by (Jarkas \& Bitar, 2012), is given below:

$$
R I I^{i}(\%)=\frac{\left(n_{4} * 4\right)+\left(n_{3} * 3\right)+\left(n_{2} * 2\right)+\left(n_{1} * 1\right)}{4 \times\left(n_{2}+n_{4}+n_{3}+n_{1}\right)} \times 100
$$

where $n_{4}, n_{3}, n_{2}, n_{1}$ are the numbers of respondents of each chosen scale $(1,2,3$, and 4$), R I I^{i}(\%)$ is the relative importance index percentage for each indicator; $i$ is the number of indicators.

\section{Results and Findings}

Reliability analysis is the analysis that can help examine the consistency of the grouped indicators to measure the variable being targeted (Field, 2009). Table 1 exhibits the outcomes of the reliability analysis of the targeted variables using the Cronbach's alpha analysis. The analysis pointed out that all the targeted variables have a fair reliability level as all the Cronbach's alpha values were above 0.7 (Nunnally \& Bernstein, 1994).

Table 1

Reliability Analysis

\begin{tabular}{ccc}
\hline & No. of Indicators & Cronbach's Alpha \\
\hline Understanding of Knowledge Management (KM) & 14 & 0.769 \\
Critical Success Factors (CSFs) & 21 & 0.942 \\
\hline Note: $\mathrm{n}=201$. & &
\end{tabular}

For a better understanding of KM, there are 14 numbers of indicators to be checked as can be found in Table 2. Table 2 implied that the average value for each indicator to gauge the understanding of KM in 
the range of 2.17 to 3.77 (Range $\mathrm{SD}=0.72$ to 1.25 ). The indication is that the indicator level was in the range of Disagree to Agree levels, since the average stayed in the range of 1.51 to 4.50. To add, a lot of the median values for indicators were 4.00. It implies that the greater part of the respondents agree with these majority indicators in this instrument. To add, the RII comparison had been completed for the set of indicators. In the analysis, the higher value of RII showed that the indicator was more understanding. Conversely, lower value of RII implied that the indicator was less understanding. The result of the RII analysis demonstrated that "KM enhances better decision making" (RII = 75.32), "KM encourages innovations" ( $\mathrm{RII}=74.93)$, "KM generates revenue growth" $(\mathrm{RII}=74.33)$, "KM creates competitive advantage" ( $\mathrm{RII}=73.53)$, and "coaching on KM is necessary" $(\mathrm{RII}=71.74)$ were the top five understanding factors about KM depending on the opinions of the respondents. Fig. 1 illustrates the line chart of the RII evaluation of the understanding of KM instrument

Table 2

Summary result of descriptive analysis and Relative Importance Index (RII) for understanding the Knowledge Management (KM)

\begin{tabular}{clcccccc}
\hline Code & \multicolumn{1}{c}{ Indicator } & Min & Max & Mean & SD & Med & RII \\
\hline C.1 & $\begin{array}{l}\text { Information and knowledge are confidential } \\
\text { and therefore need to be kept safely in personal } \\
\text { storage drive }\end{array}$ & 1 & 5 & 3.38 & 0.94 & 4.00 & 67.66 \\
C.2 & KM processes are very time consuming & 1 & 5 & 3.27 & 0.99 & 3.00 & 65.37 \\
C.3 & $\begin{array}{l}\text { KM has no benefits to the company/organiza- } \\
\text { tion }\end{array}$ & 1 & 5 & 2.31 & 1.25 & 2.00 & 46.27 \\
C.4 & I do not know what KM is & 1 & 5 & 2.17 & 1.02 & 2.00 & 43.38 \\
C.5 & $\begin{array}{l}\text { I am not aware if KM exists in my company/or- } \\
\text { ganization }\end{array}$ & 1 & 5 & 2.40 & 1.03 & 3.00 & 48.06 \\
C.6 & KM improves employee's performance & 1 & 5 & 3.50 & 0.81 & 4.00 & 69.95 \\
C.7 & KM creates competitive advantage & 1 & 5 & 3.68 & 0.75 & 4.00 & 73.53 \\
C.8 & KM encourages innovations & 1 & 5 & 3.75 & 0.76 & 4.00 & 74.93 \\
C.9 & KM generates revenue growth & 1 & 5 & 3.72 & 0.72 & 4.00 & 74.33 \\
\hline C.10 & KM enhances better decision making & 1 & 5 & 3.77 & 0.76 & 4.00 & $\mathbf{7 5 . 3 2}$ \\
C.11 & Company/organization does not need KM- & 1 & 5 & 2.72 & 0.91 & 3.00 & 54.43 \\
& based KPI & & & & & & \\
C.12 & Staff/Individuals do not need KM-based KPI & 1 & 5 & 2.62 & 0.90 & 3.00 & 52.44 \\
C.13 & Training on KM is necessary & 1 & 5 & 3.53 & 0.76 & 4.00 & 70.55 \\
\hline C.14 & Coaching on KM is necessary & 1 & 5 & 3.59 & 0.81 & 4.00 & 71.74 \\
\hline
\end{tabular}

Note: Max = Maximum value; Min = Minimum value; RII = Relative Importance Index (\%); Med = Median; SD = Standard deviation.

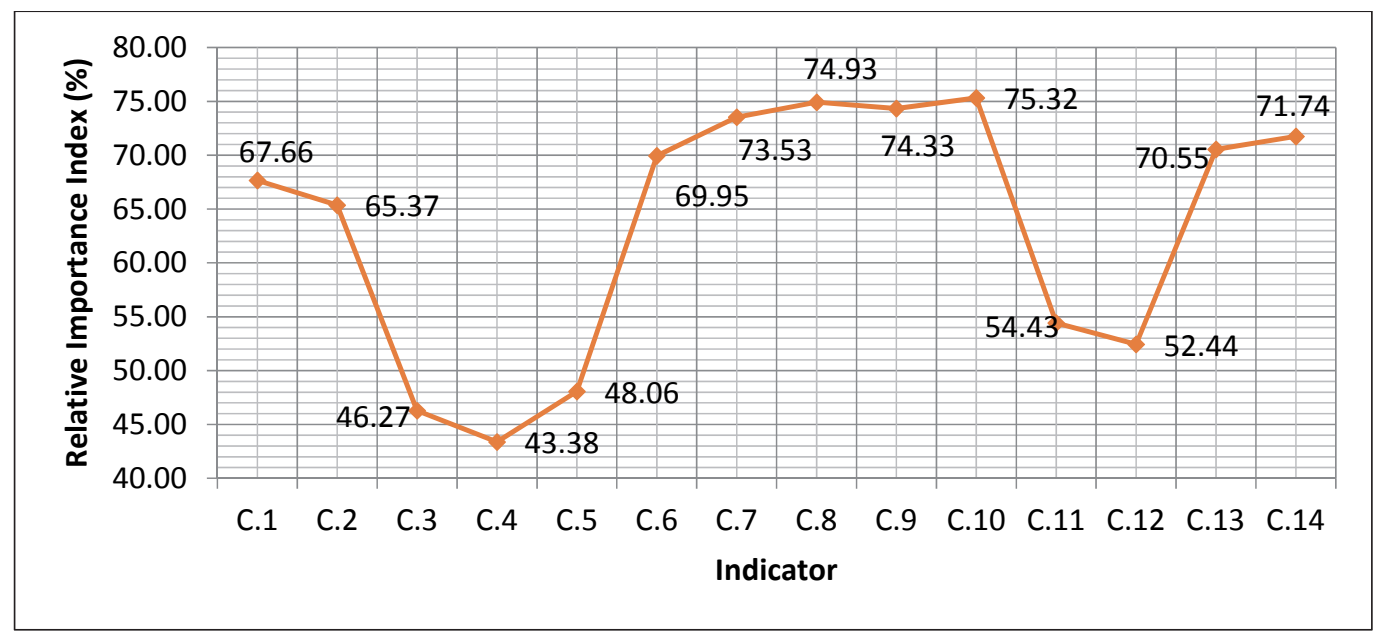

Fig. 1. Line chart of Relative Importance Index (RII) for understanding of KM indicators

To study the critical success factors of KM, there are 21 number of indicator that need to be considered. Table 3 indicated that, the average value for each indicator to measure the CSFs of KM was in the range 
of 3.73 to 4.19 (Range SD =0.54 to 0.82 ). From there, the average values were in the range of 3.51 to 4.50, suggesting that the level of the indicators was deemed important. In addition, all median values for indicators were 4.00. This gives an indication that more than 50 percent of respondents agreed with most of the indicators highlighted in the survey.

Table 3

Summary result of descriptive analysis and Relative Importance Index (RII) for CSFs of KM

\begin{tabular}{|c|c|c|c|c|c|c|c|}
\hline Code & Indicator & Min & Max & Mean & SD & Med & RII \\
\hline E.1 & Continuous organization support & 3 & 5 & 4.19 & 0.65 & 4.00 & 83.88 \\
\hline E.2 & Execution of plan & 3 & 5 & 4.06 & 0.59 & 4.00 & 81.19 \\
\hline E.3 & Knowledge and sharing culture & 2 & 5 & 4.11 & 0.62 & 4.00 & 82.19 \\
\hline E.4 & HR development & 2 & 5 & 3.95 & 0.71 & 4.00 & 78.91 \\
\hline E.5 & Financial resources & 2 & 5 & 3.92 & 0.67 & 4.00 & 78.31 \\
\hline E.6 & Technology & 2 & 5 & 4.01 & 0.54 & 4.00 & 80.20 \\
\hline E.7 & Infrastructure & 2 & 5 & 3.96 & 0.57 & 4.00 & 79.20 \\
\hline E.8 & Clear strategy on KM process & 3 & 5 & 4.04 & 0.65 & 4.00 & 80.80 \\
\hline E.9 & Leadership demonstration by senior staff/management & 3 & 5 & 4.16 & 0.63 & 4.00 & 83.28 \\
\hline E.10 & KM processes should be precise & 3 & 5 & 3.93 & 0.70 & 4.00 & 78.61 \\
\hline E.11 & Strong link to a business imperative & 3 & 5 & 3.94 & 0.69 & 4.00 & 78.81 \\
\hline E.12 & Continuous learning & 3 & 5 & 4.06 & 0.65 & 4.00 & 81.19 \\
\hline E.13 & HR management & 2 & 5 & 3.92 & 0.74 & 4.00 & 78.41 \\
\hline E.14 & Quality control and assurance & 3 & 5 & 4.00 & 0.70 & 4.00 & 80.10 \\
\hline E.15 & Marketing & 2 & 5 & 3.73 & 0.82 & 4.00 & 74.53 \\
\hline E.16 & Environmental influences - economic climates & 3 & 5 & 3.98 & 0.66 & 4.00 & 79.60 \\
\hline E.17 & Training of staff should be made compulsory & 2 & 5 & 4.03 & 0.71 & 4.00 & 80.60 \\
\hline E.18 & Measurement of KM in term of KPI & 2 & 5 & 3.91 & 0.57 & 4.00 & 78.11 \\
\hline E.19 & Benchmarking of a successful KM system nationwide & 2 & 5 & 3.80 & 0.62 & 4.00 & 76.02 \\
\hline E.20 & $\begin{array}{l}\text { Elimination of constraints that defer KM implementa- } \\
\text { tion }\end{array}$ & 2 & 5 & 3.93 & 0.70 & 4.00 & 78.51 \\
\hline E.21 & KM processes should be easy to follow & 3 & 5 & 3.96 & 0.71 & 4.00 & 79.20 \\
\hline
\end{tabular}

To add, the RII comparison was completed for indicator set. In the analysis, the higher value of RII would give an idea that the indicator was more significant. Conversely, lower value of RII showed that the indicator was less important. The result of the RII analysis established that "continuous organisation support" (RII = 83.88), "leadership demonstration by senior staff/management" (RII = 83.28), "knowledge and sharing culture" (RII = 82.19), "execution of plan" (RII = 81.19), and "continuous learning" (RII $=81.19)$ were in the top rank of CSFs about KM among the opinions given by the participants. Figure 2 represents the line chart of the RII assessment of the CSFs of KM instrument.

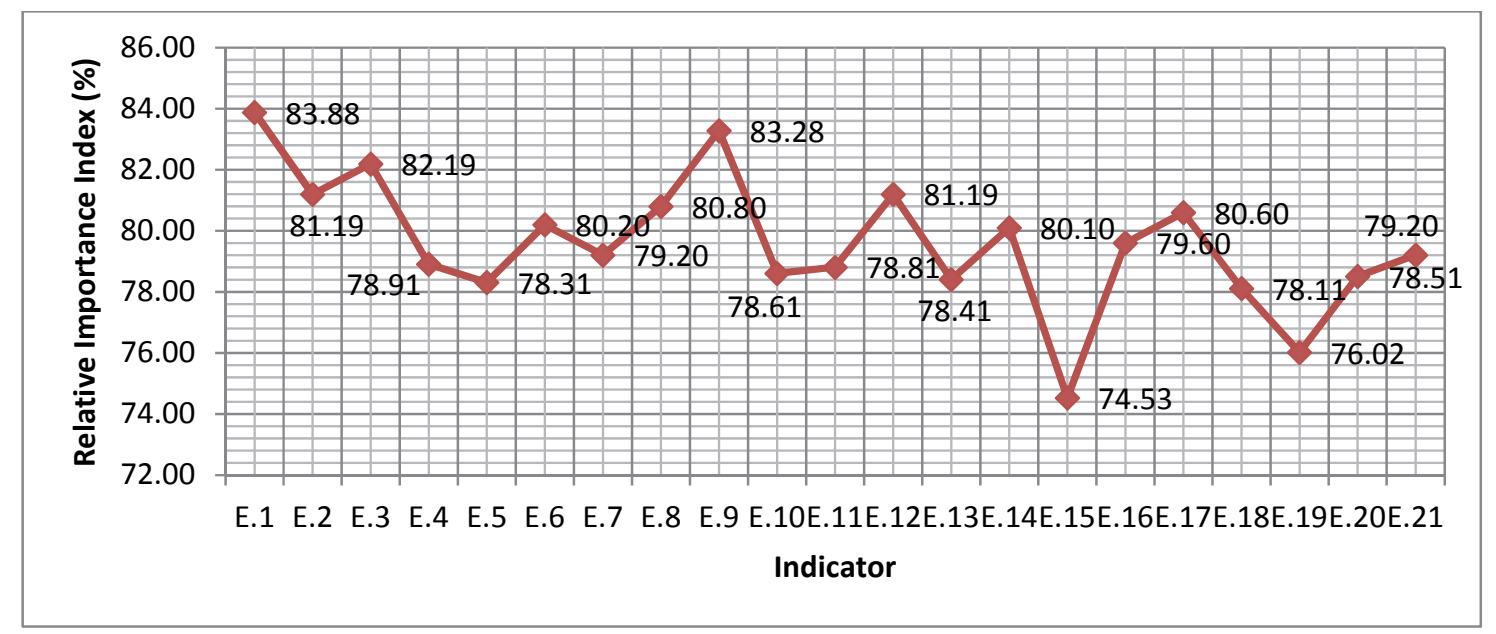

Fig. 2. Line chart of Relative Importance Index (RII) for CSFs of KM indicators 


\section{Conclusion}

Referring to ("CIDB. Construction Statistics. Construction Industry Development Board Malaysia, Kuala Lumpur," 2008), the industry of construction plays a critical role in national welfare that builds the nation for global competitiveness. The industry is made up of many components and thus is very complicated, which include thousands of developers, management teams, consultants, contractors, workers, manufacturers, suppliers and plant hirers. It is the aim of the construction industry to stand tall as a first class, ground-breaking and knowledgeable universal solution benefactor for Malaysia. However, as a complex industry with the fast-paced change of construction environment around the globe, the Malaysian construction industry also has to face various problems that have to do with quality issues, low productivity, time and cost overruns, skilled labour shortage due to high need for foreign workers, poor maintenance due to inadequate management knowledge as well as non-conducive and high accident rates on site due to poor safety awareness. In Malaysia, project failures especially involving the government construction projects mean that billions of ringgit will go to waste. Some of the failed projects boil down to abandoned, delayed and defected problems.

Skanska Sweden (2011) made a point that improvement work shall be conducted by those who have the same sentiment which is to improve operations and those who are role models within the organisation. For this initiative, these individuals were identified and selected to develop the first ten best practices. It is also observed that recognising the critical success factors (CSFs) can aid organisations to make arrangement and execute KM as a way to reduce the risk of failure and to determine these factors for implementing KM successfully. Since managing all parts of knowledge at a certain time can be unfeasible for an organisation, an ordered list of CSFs will help them list down their focus by priority. The key usage of the CSFs concept is to highlight on realising organisational revolution which will then help promote beneficial transformation. The benefits of identification of CSFs allow an easy understanding of the amount of information, help the management laid emphasis on major concern, that they can be easily monitored and utilised in connection to strategic development purposes. CSFs not only depict important strategic thinking but it should be used together with a development process as CSFs are very important in retaining people's focus. The identification of CSFs will enable organisation to allocate their limited sources of time, manpower and financial capacity appropriately. The aim of this paper has been achieved successfully to give a better understanding on KM practice amongst consultant firms who work in the construction industry in Malaysia. It is anticipated that this paper will put forth the idea of developing a conceptual framework of KM for consultant firms in the Malaysian construction industry by considering the quantitative elements of KM processes, the database system availability, business culture, company performance and efficiency. The hope is for the discussion on the understanding and CSFs of KM to be able to lead to the successful implementation of KM practice amongst Malaysian consultant firms in the construction industry.

\section{Acknowledgements}

The writers are very pleased to offer their genuine gratefulness to the Research Management Centre (RMC) of UTM, Universiti Teknologi Malaysia (UTM) and the Ministry of Education for giving the help of finance to make the publication of the paper possible. This paper is financially supported by UTM Grant for Research University (GUP) Tier 1 for research subsidizing under Cost Centre No. Q.K130000.2540.11H09.

\section{References}

Alavi, M., \& Leidner, D. (1999). Knowledge Management Systems : Issues, Challenges, and Benefits. 1(February). 
Alavi, M., \& Leidner, D. E. (2001). Knowledge management and knowledge management systems: Conceptual foundations and research issues. Management Information Systems Quarterly, 25(1), 107-136. doi:10.2307/3250961

Andi, \& Minato, T. (2003). Representing causal mechanism of defective designs: a system approach considering human errors. Construction Management and Economics, 21(3), 297-305.

Anumba Chimay, J., Egbu, C. O., \& Carrillo, P. M. (2005). Knowledge Management in Construction: Blackwell Publishing Ltd.

Bassi, L. J. (1999). Measuring knowledge management effectiveness. In: J. Hermans (Ed.) The Knowledge Management Yearbook 1999-2000 (USA, Butterworth-Heinemann), pp. 422-427.

Burton-Jones, A. (1999). Knowledge Capitalism: Business, Work, and Learning in the New Economy. New York: Oxford University Press, Inc.

Cavaleri, S. A. (2004). Leveraging organizational learning for knowledge and performance. The Learning Organization, 11(2), 159-176. doi:10.1108/09696470410521619

Chawla, V., Chanda, A., Angra, S \& Chawla, G. (2018). The sustainable project management: A review and future possibilities. Journal of Project Management, 3(3), 157-170.

Chen, S., Duan, Y., Edwards, J. S., \& Lehaney, B. (2006). Toward understanding inter-organizational knowledge transfer needs in SMEs: insight from a UK investigation. Journal of Knowledge Management, 10(3), 6-23. doi:10.1108/13673270610670821

Choi, Y. S. (2000). An empirical study of factors affecting successful implementation of knowledge management (University of Nebraska).

Chua, D. K. H. (1999). Critical success factors for different project objectives. Journal of construction Engineering and Management, 125(3), 142-150.

CIDB. (2008). Construction Statistics. Construction Industry Development Board Malaysia, Kuala Lumpur.

Cohen, W. M., \& Levinthal, D. A. (1990). Absorptive capacity: A new perspective on learning and innovation. Administrative Science Quarterly, Special Issue: Technology, Organizations, and Innovation (Mar., 1990), 35(1), 128-152.

Davenport, T. H., \& Prusak, L. (1998). Working knowledge: How organizations manage what they know: Harvard Business Press, 1998 - Business \& Economics.

Davenport, T. H., \& Völpel, S. C. (2001). The rise of knowledge towards attention management. Journal of Knowledge Management, 5(3), 212-222. doi:10.1108/13673270110400816

DeTienne, K. B., \& Jackson, L. A. (2001). Knowledge management: Undrestanding therory and developing strategy. Competitiveness Review, 11(1), 1-11. doi:10.1108/eb046415

Dillman, D. A., Redline, C. D., \& Carley-Baxter, L. R. (1999). Influence of type of question on skip pattern compliance in self-administered questionnaires. In Joint Statistical Meetings of the American Statistical Association, Indianapolis.

Field, A. (2009). Discovering statistics using SPSS. Sage publications.

Finnerean, T. (1999). A component-based knowledge management system. Robert S. Seiner http://www.tdan. com/i009hy04.htm. Accessed 1 June 2001.

Fiol, C. M., \& Lyles, M. A. (1985). Organizational learning Academy of Management Review, 10 (4), 803-813. Gartner, W, B,(1985). A conceptual framework for describing the phenomenon of new venture creation, Academy of Management Review I, 696-706.

Grant, R. (1996). Toward a knoweldge-based theory of the firm. Strategic Management Journal, 17(S2), 109-122. doi:10.1002/smj.4250171110

Hair, J. F., Anderson, R. E., Babin, B. J., \& Black, W. C. (2010). Multivariate data analysis: A global perspective. Upper Saddle River, NJ: Pearson, 7.

Hansen, M. T. (1999). The Search-Transfer Problem : The Role of Weak Ties in Sharing Knowledge across Organization Subunits Author ( s ): Morten T . Hansen Source : Administrative Science Quarterly, Vol . 44 , No . 1 ( Mar ., 1999 ), pp . 82-111 Published by : Sage Publicatio. 44(1), 82111.

Hislop, D. (2003). Linking Human Resource Management and Knowledge Management Via Commitment. Employee Relations, 25(2), 182-202. 
Huber, G. P. (1991). Organizational learning: The contributing processes and the literatures. Organization Science, 2(1), 88-115.

Hult, G. T. M., Hurley, R. F., Giunipero, L. C., \& Nichols, E. L., Jr. (2000). Organizational learning in global purchasing: A model and test of internal users and corporate buyers. Decision Sciences, 31(2), 293-325.

Ikujirō, N., \& Takeuchi, H. (1995). The Knowledge-creating Company: How Japanese Companies Create the Dynamics of Innovation: Oxford University Press, 1995 - Business \& Economics.

Jarkas, A., \& Bitar, C. (2012). Factors affecting construction labour productivity in Kuwait. Journal of Construction Engineering and Management, ASCE, 138(7), 811-821.

Johnson, D. W., \& Johnson, R. T. (1989). Cooperation and competition: Theory and research. Edina, MN: Interaction.

Johnson, D. W., Johnson, R. T., Buckman, L. A., \& Richards, P. S. (1988). The effect of prolonged implementation of cooperative learning on social support within the classroom. Journal of Psychology, 119(5), 405-411.

Johnson, D. W., Johnson, R. T., \& Holubec, E. (1989). Circles of learning: Cooperation in the classroom (3rd ed.). Edina, MN: Interaction.

Kamara, J. M., Anumba, C. J., \& Carrillo, P. M. (2002). A CLEVER approach to selecting a knowledge management strategy. International Journal of project management, $20(3), 205-211$. doi:https://doi.org/10.1016/S0263-7863(01)00070-9

Kazi, S. A. (2005). Knowledge management in the construction industry: A socio-technical perspective: Idea Group Publishing.

Kleindl, B. (2000). Strategic Electronic Marketing: Managing E-Business (1st editio ed.): SouthWestern Pub; 1st edition (April 27, 2000).

Liebowitz, J. (1999). Key ingredients to the success of an organization's knowledge management strategy. Knowledge and Process Management, 6(1), pp. 37-40.

Manasco, B. (1999). The Knowledge Imperative: Leverage it or Lose it.

Mason, D., \& Pauleen, D. J. (2003). Perceptions of knowledge management: a qualitative analysis. Journal of Knowledge Management, 7(4), 38-48. doi:10.1108/13673270310492930

McQueen, R. A., \& Knussen, C. (2002). Research methods for social science: A practical introduction. Pearson Education.

Morey, D. (1998). Knowledge Management Architecture.

Nunnally, J. C., \& Bernstein, I. H. (1994). The assessment of reliability. Psychometric Theory, 3(1), 248-292.

Pallant, J. (2010). SPSS survival manual: A step by step guide to data analysis using SPSS. Maidenhead.

Rockart, J. F. (1979). Chief executives define their own data needs. Harvard Business Review, 57(2)(Mar-Apr), 81-93.

Roy, M. C. (2001). Support systems for knowledge workers: The need for new development approaches. Journal of Knowledge Management Practice, August 2001.

Sadeghi, A \& Rad, F. (2018). The role of knowledge-oriented leadership in knowledge management and innovation. Management Science Letters, 8(3), 151-160.

Saraph, J. V., Benson, P. G., \& Schroeder, R. G. (1989). An instrument for measuring the critical factors of quality management. Decision sciences, 20(4), 810-829.

Schulz, M. (2001). The uncertain relevance of newness: Organizational learning and knowledge flows. Academy of Management Journal, 44(4), 661-681.

Shankar, R., Singh, Gupta, A., \& Narain, R. (2003). Strategic planning for knowledge management implementation in engineering firms. Work Study, 52(4), 190-200. doi:10.1108/00438020310479036

Skanska Sweden, A. B. (2011). No Title. from Presentation Skanska Sverige: Unpublished internal document, Retrieved May 24, 2011-Retrieved May 2024, 2011.

Skyme, D. (2000). Knowledge Management: Making Sense of an Oxymoron. 
Skyrme, D., \& Amidon, D. (1997). The Knowledge Agenda. Journal of Knowledge Management, 1(1), 27-37.

Snowden, D. (1999). Liberating knowledge. Liberating Knowledge: Reeves J. London: Caspian Publishing.

Storey, J., \& Quintas, P. (2001). Knowledge management and HRM. Human Resource Management: A Critical Text. Cornwall: T.

Trussler, S. (1998). The rules of the game. Journal of Business Strategy, 19(1), 16-19.

Valmohammadi, C. (2010). Identification and prioritization of critical success factors of knowledge management in Iranian SMEs: An experts' view. African Journal of Business Management, 4(6), 915-915.

Wiig, K. M. (1997). Knowledge Management: An Introduction and Perspective. Journal of Knowledge Management, 1(1), 6-14. doi:10.1108/13673279710800682

Wright, P. M., Dunford, B. B., \& Snell, S. A. (2005). Human Resource Management And Knowledge. In: Salaman, G., Storey, J And Billsberry, J. (Eds. ). Strategic Human Resource Management: Theory And Practice. Open University: London.

Zanjani, M. S., Mehrasa, S., \& Modiri, M. (2008). Organizational dimensions as determinant factors of KM approaches in SMEs. International Journal of Social, Behavioral, Educational, Economic, Business and Industrial Engineering, 2(9), 389-394.

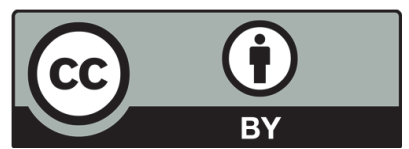

(C) 2018 by the authors; licensee Growing Science, Canada. This is an open access article distributed under the terms and conditions of the Creative Commons Attribution (CC-BY) license (http://creativecommons.org/licenses/by/4.0/). 